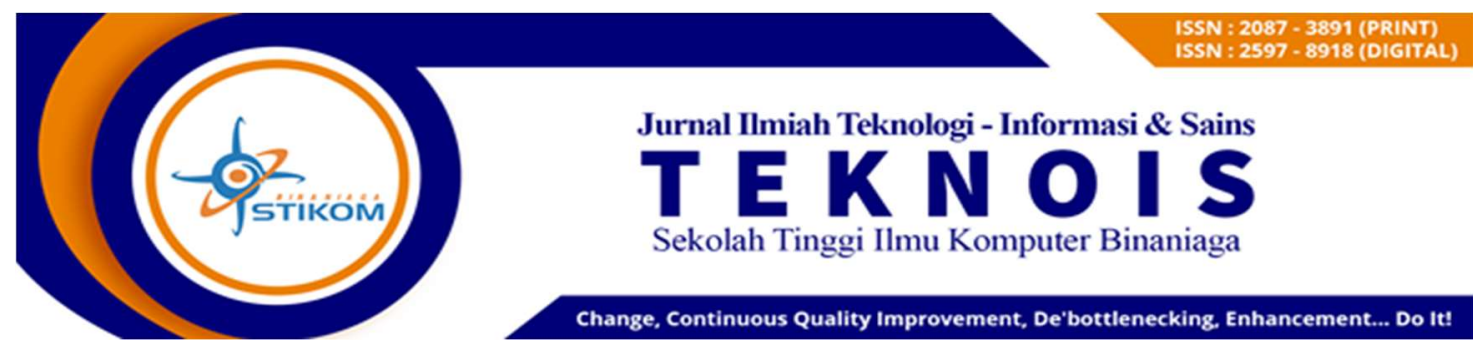

Article DOI : 10.36350/jbs.v10i1.80

Received: Maret; Accepted : April; Published : Mei

\title{
Penerapan Algoritma Spatial Map Matching dengan API Menggunakan GPS untuk Posisi Tumpangan Kendaraan
}

\author{
Farhan Zayid $^{1^{*}}$, Egi Ferdiana ${ }^{2}$ \\ ${ }^{1}$ Teknik Informatika/STIKOM Binaniga \\ Email: farhan@stikombinaniaga.ac.id \\ ${ }^{2}$ Teknik Informatika/STIKOM Binaniga \\ Email: egi.ferdians11@gmail.com
}

\begin{abstract}
ABSTRAK
Di kota pariwisata seperti Kota Bogor, kemacetan lalu lintas sudah tidak terdengar asing lagi di telinga masyarakat Kota Bogor. Diperlukan solusi untuk mengatasi permasalahan kemacetan lalu lintas yang disebabkan oleh jumlah kendaraan yang melebihi kapasitas jalan. Pada penelitian ini dibangun aplikasi Neon yaitu jejaring sosial berbasis perangkat komunikasi bergerak yang memudahkan berbagi kendaraan dalam tujuan perjalanan yang sama. Penelitian ini penulis menerapkan suatu algoritma yaitu Algoritma Spatial Map Matching yang fungsinya sebagai penentuan titik koordinat yang presisi pada rute perjalanan yang ditampilkan pada maps digital yaitu Google Maps. Berdasarkan hasil pengujian kelayakan yang telah disimpulkan bahwa secara fungsional seluruh proses pada aplikasi penerapan Algoritma Spatial Map Matching sebagai cara penentuan titik koordinat yang presisi untuk aplikasi tumpangan kendaraan telah berjalan sesuai yang diharapkan. Sebagaimana dari 15 data titik yang ditentukan, data jarak dari penerapan Algoritma Spatial Map Matching lebih dekat dibandingkan dengan data jarak aplikasi sebelumnya (nebengers) terhadap posisi tempat/jalan terdekat yang sudah ditentukan yaitu dengan rata-rata jaraknya 1.71 Meter. Sedangkan hasil selisih jarak yang dihasilkan memiliki jarak yang cukup jauh antara jarak data dari posisi titik pada aplikasi sebelumnya (nebengers) dengan posisi titik yang sudah diterapkan Algoritma Spatial Map Matching. Dapat disimpulkan bahwa Algoritma Spatial Map Matching dapat menentukan titik posisi yang lebih presisi dengan persentase kelayakan penelitian sebesar $82.85 \%$.
\end{abstract}

Keywords: Algoritma Spatial Map Matching, Posisi Tumpangan Kendaraan, Aplikasi Android Nebeng Online.

\section{A. PENDAHULUAN}

1. Latar Belakang

Salah satu teknologi yang ada di smartphone yaitu GPS. GPS (Global Positioning System) merupakan sistem yang menggunakan bantuan satelit untuk mengetahui posisi atau letak suatu permukaan bumi. Semua hal bisa diketahui oleh sistem GPS. Dengan bantuan satelit untuk memantau posisi permukaan bumi. GPS sudah banyak diimplementasikan untuk kebutuhan sehari-hari diantaranya yaitu pelacak kendaraan, memantau gempa dan bencana, sistem informasi geografis wilayah, navigasi jalan, digunakan dalam bidang militer dan petunjuk arah lautan. GPS memilki peluang untuk dikembangkan maupun diimplementasikan pada kasus lain. Artinya dalam hal ini teknologi GPS dari smartphone masih bisa dikembangkan dan dimanfaatkan untuk menyelesaikan masalah yang terjadi di sekitar kita dan memberikan kemudahan bagi penggunannya. 
Masalah yang dapat kita ambil untuk menyelesaikannya dengan menggunakan teknologi GPS pada smartphone yaitu masalah kemacetan yang diakibatkan terlalu banyaknya kendaraan yang sudah melewati batas volume jalan. Bagi negara berkembang utamanya yang sangat dikeluhkan dalam permasalahan bertransportasi ini. Hal ini dikarenakan pertumbuhan penduduk di setiap negara semakin lama semakin meningkat, sehingga berimbas kepada pengguna jasa transportasi yang meningkat tajam. Tidak terkecuali di Indonesia sebagai salah satu negara berkembang sekaligus salah satu negara dengan populasi terbesar di dunia. Dimana lebih banyak transportasi yang digunakan masyarakat Indonesia yaitu menggunakan kendaraan pribadi dibandingkan dengan kendaraan umum. Berikut statik perkembangan jumlah kendaraan bermotor menurut jenisnya dari tahun 2010-2017 oleh BPS :

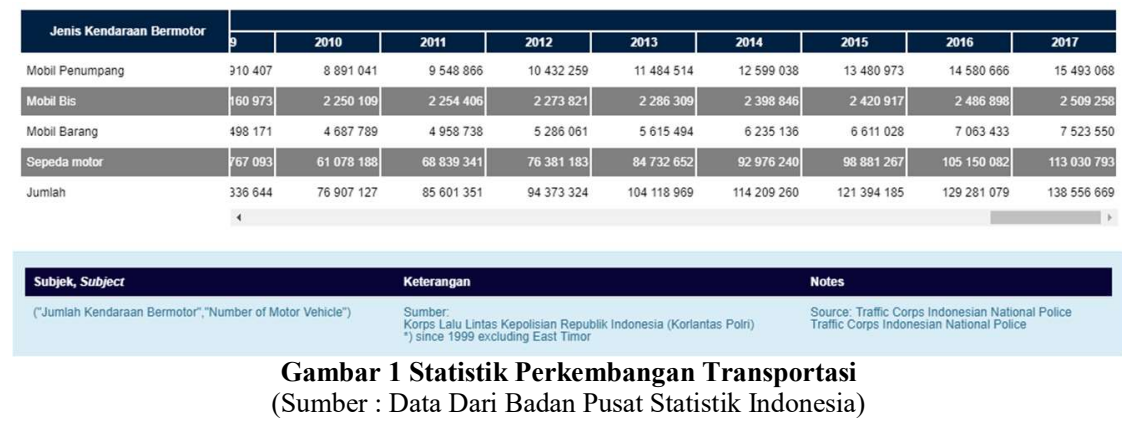

Dari gambar diatas disimpulkan bahwa pengguna kendaraan sepeda motor menjadi yang terbanyak dibandingkan jenis lainnya dan mobil penumpang atau kendaraan umum mempunyai jumlah yang lebih sedikit dari pengguna sepeda motor. Jadi bisa di bayangkan pengguna transportasi pribadi lebih banyak dibandingkan pengguna transportasi umum yang dapat menimbulkan berbagai macam masalah diantaranya polusi udara yang semakin banyak yang membuat kotornya udara disekitar yang dikarena oleh asap kendaraan. Namun masalah umum yang sebenarnya yang ditimbulkan dari meningkatnya transportasi di setiap daerah di Indonesia yaitu kemacetan. Dari permasalah tersebut bukan berarti tidak adanya upaya pemerintah untuk mengatasi kemacetan seperti peningkatan kapasitas jalan, dianjurkan untuk menggunakan angkutan umum, dan pembatasan kendaraan pribadi. Namun sampai saat ini tindakan tersebut belum terlihatnya dampak positif yang signifikan artinya masih terjadi kemacetan dimana-mana padahal aturan tersebut sudah dilakukan.

Selain itu sudah banyak upaya dari masyarakat untuk mengurangi angka kendaraan dijalan raya yang menyebabkan kemacetan yaitu dengan membentuk suatu komunitas. Komunitas ini bukan sekedar komunitas biasa tetapi komunitas yang terbentuk untuk menyelesaikan masalah sosial seperti kemacetan. Komunitas yang terbentuk dari masalah kemacetan yaitu komunitas nebeng. Komunitas nebeng adalah komunitas berbagi kendaraan dalam perjalanan tertentu dengan perjanjian sebelumnya. Saat ini ada komunitas nebeng yang didukung dengan teknologi informasi yaitu www.nebengers.com yang merupakan situs menyediakan info berbagi kendaraan. Untuk mengakses aplikasi ini harus melakukan pendaftaran dahulu. Kelemahan aplikasi ini adalah informasi pencarian pemberi tumpangan tidak detil dan tata letak posisi kendaraan kurang sesuai.

Dengan adanya penelitian ini kelemahan dari aplikasi tersebut harus dapat diatasi dengan menciptakannya sarana atau aplikasi baru untuk komunitas nebeng yang lebih tepat dan cepat untuk pencarian tumpangannya. Perlu adanya metode atau algoritma khusus untuk memperbaiki posisi dalam sebuah perangkat GPS pada smartphone seperti menggunakan algoritma Spatial Map Matching untuk meminimalisir kesalahan dalam menampilkan posisi kendaraan. Hal ini menghindari akurasi perangkat GPS pada smartphone yang kurang baik, karena biasanya terjadi penyimpangan.

\section{Permasalahan}

Dari uraian latar belakang di atas, maka dapat diidentifikasi masalah dalam penelitian ini adalah Belum presisinya titik koordinat yang didapatkan sesuai dengan posisi lokasi yang aktual.

\section{Tujuan}

Adapun tujuan penelitian ini adalah 
a. Memperbaiki posisi titik koordinat pada Maps Digital (Google Maps).

b. Mendapatkan titik koordinat pada Maps Digital (Google Maps) yang sesuai dengan posisi tumpangan kendaraan.

\section{Tinjauan Pustaka}

a. Spatial Matching

Menurut Maftukhin (2018, p.13) menyatakan bahwa spatial matching merupakan salah satu dari beberapa algoritma map matching yang menggunakan data GPS pada peta digital dan menggunakan analisa spasial geografis untuk membuat kandidat grafik berdasar data GPS yang ada, lalu setelahnya akan dilakukan perhitungan jarak terdekat untuk menentukan atau mencocokkannya grafik tersebut ke dalam peta yang asli. Sebelum membahas spatial matching lebih jauh, lebih baiknya membahas terlebih dahulu konsep analisa spasial.

b. Global Positioning System (GPS)

Adalah suatu sistem navigasi menggunakan ebih dari 24 satelit MEO (Medium Earth Orbit atau Middle Earth Orbit) yang mengelilingi bumi sehingga penerima-penerima sinyal di permukaan bumi dapat menangkap sinyalnya. GPS mengirimkan sinyal gelombang mikro ke Bumi. Sinyal ini diterima oleh alat penerima di permukaan, dan digunakan untuk menentukan letak, kecepatan,arah, dan waktu.Satelit mengorbit pada ketinggian 12.000 mil di atas bumi dan mampu mengelilingi bumi dua kali dalam 24 jam. Satelit GPS secara kontinyu mengirimkan sinyal radio digital yang mengandung data lokasi satelit dan waktu, pada penerima yang berhubungan. Satelit GPS dilengkapi dengan jam atom yang mempunyai ketepatan waktu satu per satu juta detik. Berdasar informasi ini, stasiun penerima mengetahui berapa lama waktu yang digunakan untuk mengirim sinyal sampai kepada penerima di bumi. Semakin lama waktu yang digunakan untuk sampai ke penerima, berarti semakin jauh posisi satelit dari stasiun penerima.

c. API (Application Programing Interface)

Secara umum API merupakan ekspresi terfokus keseluruhan fungsional dalam suatu modul software yang dapat diakses oleh orang yang membutuhkan dengan cara yang telah ditentukan layanan. Representasi terfokus dari fungsi yang dideklarasikan dalam API dimaksudkan untuk menyediakan rangkaian layanan yang spesifik untuk target tertentu. Jika dalam satu modul memiliki API ganda, hal ini sudah menjadi hal yang umum karena setiap API dimaksudkan untuk penggunaan yang spesifik dari modul terkait (Rama dan Avinash, 2015).

\section{B. METODE}

\section{Prosedur Pengembangan}

Prosedur pengembangan merupakan langkah-langkah yang dilakukan dalam proses pengembangan. Langkah-langkah tersebut dapat dilihat pada gambar dibawah ini.

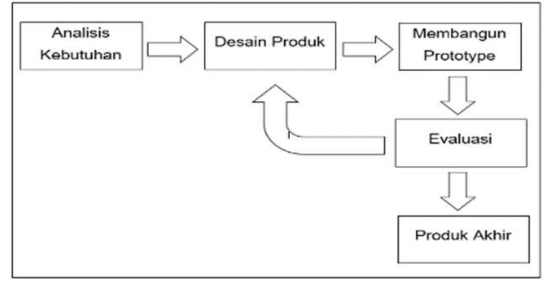

Gambar 2. Prosedur Pengembangan

Dapat dijelaskan prosedur pengembangan dari penelitian ini sebagaimana yang ditunjukkan oleh gambar 2 :

a. Analisa Kebutuhan, yaitu proses analisis untuk mendapatkan data yang dibutuhkan, proses analisis dapat berupa observasi, wawancara, studi pustaka, dan pencarian penelitian yang dianggap relevan.

b. Desain Produk, yaitu pendefinisian dari kebutuhan - kebutuhan fungsional dan persiapan untuk rancang bangun implementasi; menggambarkan bagaimana sistem prediksi jumlah produksi paket menu dibentuk.

c. Membangun Prototype, yaitu tahap dimana membangun prototype.

d. Evaluasi, yaitu produk dievaluasi oleh pengguna. 
e. Produk, yaitu produk awal yang telah dievaluasi kepada pengguna, jika ada kesalahan maka kembali lagi pada tahap evaluasi.

f. Produk Akhir, yaitu produk yang telah melalui tahap uji coba bahwa produk layak digunakan.

\section{Kerangka Uji Coba}

Uji coba produk dimaksudkan untuk mengumpulkan data yang dapat digunakan sebagai dasar untuk menetapkan tingkat keefektifan, efiiensi dan daya tarik dari produk yang dihasilkan.

a. Desain Uji Coba

Pada penelitian pengembangan ini dilakukan tahapan pengujian, yaitu uji coba yang dilakukan terhadap ahli sistem informasi dan mahasiswa di STIKOM Binaniaga Bogor.

1) Uji Coba Ahli Teknologi Informatika

Pengujian kepada ahli teknologi informatika untuk mereview produk awal sistem, uji coba dilakukan dengan menyebarkan kuesioner.

2) Uji Coba Pengguna

Pengujian kepada pengguna dilakukan untuk mengetahui kelayakan dan ketepatan informasi yang dihasilkan, uji coba dilakukan dengan menyebarkan kuesioner kepada pengguna yaitu Komunitas Nebeng.

b. Subjek Uji Coba

Karakteristik subjek uji coba perlu diidentifikasi secara jelas dan lengkap, termasuk cara pemilihan subjek uji coba. Subjek uji coba dapat terdiri dari ahli dibidang aplikasi android, dan sasaran pemakai komunitas nebeng. Subjek uji coba yang dilibatkan harus diidentifikasi karakteristiknya secara jelas dan lengkap, tetapi terbatas dalam kaitannya dengan produk yang dikembangkan. Teknik pemilihan subjek uji coba juga perlu dikemukakan lebih rinci.

\section{Jenis Data}

a. Jenis Data Ahli

Jenis data yang diharapkan dari ahli materi adalah data yang berhubungan dengan teknis pengembangan sebuah alat dan juga sebuah aplikasi yang dapat dinilai dari segi usability, fungtionality, dan komunikasi visual.

b. Jenis Data Pengguna

Jenis data yang diharapkan dari pengguna adalah data yang berhubungan dengan pengalaman pengguna (User Experience) yakni dari segi tampilan, kemudahan dalam penggunaannya, dan manfaat dari adanya produk tersebut.

\section{Instrumen Pengumpulan Data}

Menurut Suharsimi Arikunto instrumen penelitian merupakan alat bantu yang dipilih dan digunakan oleh penelitian dalam melakukan kegiatannya untuk mengumpulkan data agar kegiatan tersebut menjadi sistematis dan dipermudah olehnya. Adapun instrumen yang akan digunakan dalam penelitian pengembangan ini yaitu kuesioner. Kuesioner tersebut merupakan instrumen bagi pengguna.

Tabel 1. Kisi-Kisi Instrumen Kuesioner Untuk Ahli Sistem Informasi

\begin{tabular}{|c|c|c|c|}
\hline No & Aspek Penilaian & Indikator & $\begin{array}{c}\text { Jumlah } \\
\text { Butir }\end{array}$ \\
\hline \multirow{2}{*}{1} & \multirow{2}{*}{ Komponen Input } & User Interface & 1 \\
\hline & & Interaksi Sistem & 1 \\
\hline \multirow{2}{*}{2} & \multirow{2}{*}{ Komponen Model } & Prosedur Sistem & 1 \\
\hline & & Logika Program & 1 \\
\hline \multirow{2}{*}{3} & \multirow{2}{*}{ Komponen Output } & Ketepatan Informasi & 1 \\
\hline & & Kekinian Informasi & 1 \\
\hline \multirow[b]{2}{*}{4} & \multirow{2}{*}{ Komponen Teknologi } & Waktu Respon & 1 \\
\hline & & Keluwesan Sistem ( Sistem Flexibility ) & 1 \\
\hline 5 & Komponen Control & Keamanan Sistem & 1 \\
\hline 6 & Arsitektur Data & Isi-isi Basis Data (Database Contents) & 1 \\
\hline
\end{tabular}

Tabel 2 Kisi-Kisi instrument Kuesioner Untuk pengguna

\begin{tabular}{|c|c|c|c|}
\hline \multirow{2}{*}{ No. } & Aspek Penilaian & Indikator & $\begin{array}{c}\text { Jumlah } \\
\text { Butir }\end{array}$ \\
\hline \multirow{2}{*}{1} & \multirow{2}{*}{ Kualitas Informasi } & Kelengkapan (Completeness) & 1 \\
\cline { 3 - 4 } & & Keseksamaan(Precision) & 1 \\
\hline
\end{tabular}


Volume 10 Number 1. Mei 2020 Page. 45-56

Journal Homepage : http://teknois.stikombinaniaga.ac.id/index.php/JBS

DOI Link : http://doi.org/10.36350/jbs.v10i1

\begin{tabular}{|c|c|c|c|}
\hline & & Reabilitas(Reability) & 1 \\
\hline & & Keluaran(Format of Output) & 1 \\
\hline \multirow{6}{*}{2} & \multirow{6}{*}{ Kualitas Sistem } & Fleksibilitas Sistem (System Flexibility) & 1 \\
\hline & & Integrasi Sistem (System Integration) & 1 \\
\hline & & Waktu Untuk Merespon (Time to Respon) & 1 \\
\hline & & Pemulihan Kesalahan (Error Recovery) & 1 \\
\hline & & Kenyamanan Akses (Convinience of access) & 1 \\
\hline & & Bahasa (Language) & 1 \\
\hline \multirow{3}{*}{3} & \multirow{3}{*}{ Kualitas Layanan } & Jaminan (Assurance) & 1 \\
\hline & & Empati (Emphaty) & 1 \\
\hline & & Tanggapan (Responsiveness) & 1 \\
\hline \multirow{2}{*}{4} & \multirow{2}{*}{ Penggunaan } & Waktu Penggunaan Harian (Daily Use Time) & 1 \\
\hline & & Frekuensi Penggunaan (Frequency of Use) & 1 \\
\hline \multirow{2}{*}{5} & \multirow{2}{*}{ Kepuasaan Pengguna } & Pembelian Ulang (Repeat Purchase) & 1 \\
\hline & & Pengunjung Ulang (Repeat Visit) & 1 \\
\hline \multirow{3}{*}{6} & \multirow{3}{*}{ Keuntungan Bersih } & $\begin{array}{l}\text { Kecepatan Menyelesaikan Tugas (Speed of Acomplishing } \\
\text { Task) }\end{array}$ & 1 \\
\hline & & Kinerja Pekerjaan (Job Peformace) & 1 \\
\hline & & Efektivitas (Efectiveness) & 1 \\
\hline
\end{tabular}

Teknik pengolahan data pada penelitian pengembangan ini menggunakan pengukuran skala likert. Skala Likert merupakan metode skala bipolar, yang menentukan positif atau negatif respon pada sebuah pernyataan. Skala Likert atau Likert Scale adalah skala penelitian yang digunakan untuk mengukur sikap dan pendapat. Dengan skala likert ini, responden diminta untuk melengkapi kuesioner yang mengharuskan mereka untuk menunjukkan tingkat persetujuannya terhadap serangkaian pertanyaan. Pertanyaan atau pernyataan yang digunakan dalam penelitian ini biasanya disebut dengan variabel penelitian dan ditetapkan secara spesifik oleh peneliti. Nama Skala ini diambil dari nama penciptanya yaitu Rensis Likert, seorang ahli psikologi sosial dari Amerika Serikat.

Tingkat persetujuan yang dimaksud dalam skala Likert ini terdiri dari 5 pilihan skala yang mempunyai gradasi dari Sangat Setuju (SS) hingga Sangat Tidak Setuju (STS). 5 pilihan tersebut diantaranya adalah :

Tabel 3. Tabel Skala Likert

\begin{tabular}{|c|c|c|}
\hline No. & Kategori & Skor \\
\hline 1 & Sangat Setuju (SS) & 5 \\
\hline 2 & Setuju (S) & 4 \\
\hline 3 & Ragu-ragu (RG) & 3 \\
\hline 4 & Tidak Setuju (TS) & 2 \\
\hline 5 & Sangat Tidak Setu (STS) & 1 \\
\hline
\end{tabular}

\section{Teknik Analisa Data}

Analisis data adalah proses mencari dan menyusun secara sistematis data yang diperoleh dari hasil wawancara, catatan lapangan, dan bahan-bahan lain, sehingga dapat mudah dipahami, dan temuannya dapat diinformasikan kepada orang lain (Bogdan dalam Sugiyono, 2013:244). Analisis data ini menggunakan teknik analisis deskriptif, data yang diperoleh melalui kuesioner dengan analisis deskriptif akan diuraikan secara naratif. Jenis data yang diperoleh dari hasil uji kelayakaan (Validasi) oleh pengguna yaitu data kuantitatif, data kuantitatif berupa angka-angka mulai dari 1 hingga 5 berdasarkan skala likert yang kemudian akan di presentasekan.

Teknik analisis data yang digunakan untuk menganalisis data hasil penilaian kelayakan adalah dengan teknik analisis deskriptif. Adapun teknik deskriptif presentase yang akan digunakan, dapat dituliskan sebagai berikut:

Keterangan :

$$
\text { Persentase }=\frac{\sum(\text { Jawaban } x \text { Bobot tiap pilihan })}{n \times \text { Bobot tertinggi }}
$$

$\Sigma=$ Jumlah

$\mathrm{N}=$ Jumlah seluruh item angket

Jenjang kualifikasi kriteria kelay akan untuk menyimpulkan hasil validasi adalah sebagai berikut:

Tabel 4 Konversi Tingkat Pencapaian

\begin{tabular}{|c|c|}
\hline Tingkat Ketercapaian & Kualifikasi \\
\hline $90 \%-100 \%$ & Sangat Layak \\
\hline $75 \%-89 \%$ & Layak \\
\hline $65 \%-74 \%$ & Cukup Layak \\
\hline
\end{tabular}


Volume 10 Number 1. Mei 2020 Page. 45-56

Journal Homepage : http://teknois.stikombinaniaga.ac.id/index.php/JBS

DOI Link : http://doi.org/10.36350/jbs.v10i1

\begin{tabular}{|c|c|}
\hline $55 \%-64 \%$ & Kurang Layak \\
\hline $0 \%-54 \%$ & Tidak Layak \\
\hline \multicolumn{2}{|c|}{ (Adaptasi dari Sudjana,2005,hlm.35) }
\end{tabular}

\section{HASIL DAN PEMBAHASAN}

\section{HASIL}

Berdasarkan pengumpulan dan wawancara didapati alur system seperti dibawah ini :

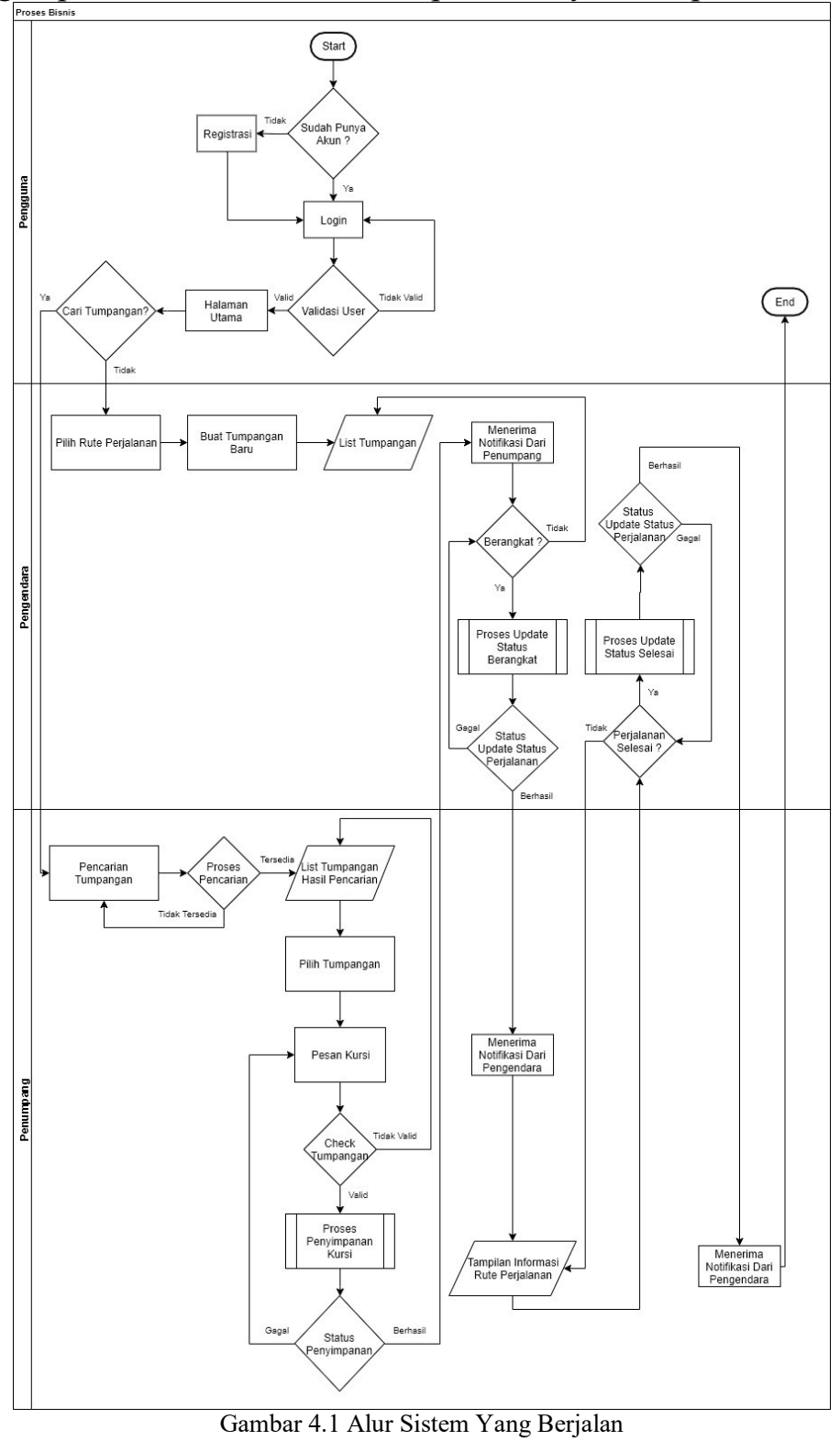

Berdasarkan gambar 4.1 diawali dengan apabila anda belum memiliki akun diwajibkan untuk mendaftar terlebih dahulu dan apabila sudah memiliki akun maka prosesnya langsung menuju login saja. Jika berhasil tervalidasi maka anda akan menuju ke halaman utama. Selanjutnya user akan ditawarkan 2 opsi yaitu pengendara dan penumpang. Jika sebagai pengendara user diharuskan membuat perjalanan terlebih dahulu seperti yang di jelaskan pada gambar di atas. Jika user sebagai penumpang maka user akan mencari tumpangan sesuai tempat awal dan tujuan lalu memesan kursi pada tumpangan tersebut. Jika proses pengecekan tumpangan valid maka penumpang akan mengirimkan notifikasi kepada pengendara yang memiliki tumpangan tersebut. setelah itu proses mengupdate status tumpangan akan dilakukan oleh pengendara dan masing-masing akan mengirim notifikasi kepada penumpang sebagai tanda berangkat dan selesainya tumpangan yang telah dipesan.

berdasarkan data yang didapat dikembangkanlah system sebagai berikut : 
Volume 10 Number 1. Mei 2020 Page. 45-56

Journal Homepage : http://teknois.stikombinaniaga.ac.id/index.php/JBS

DOI Link : http://doi.org/10.36350/jbs.v10i1

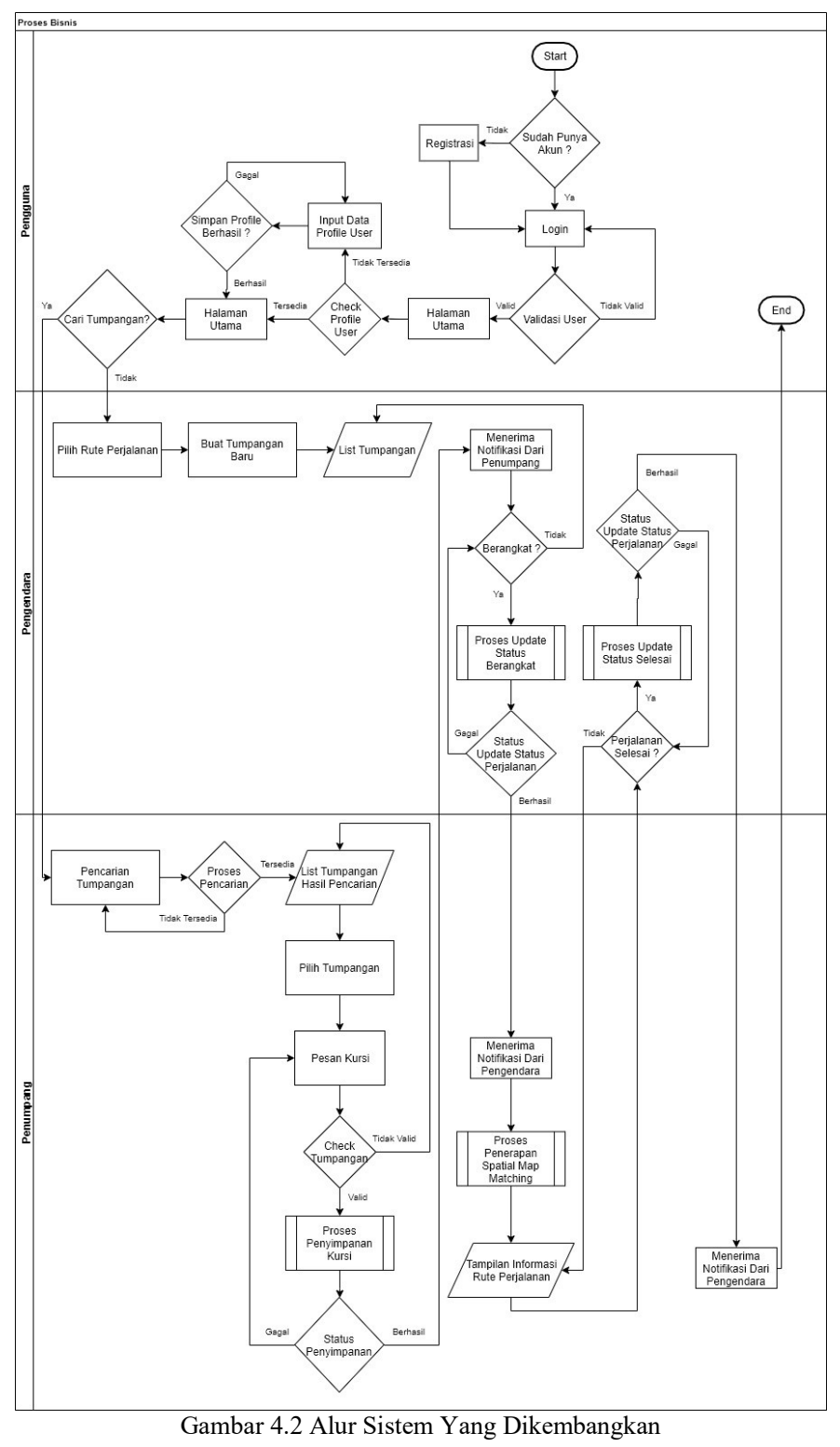

Berdasarkan gambar 4.2 hampir sama dengan alur sistem yang lama yaitu diawali dengan apabila anda belum memiliki akun diwajibkan untuk mendaftar terlebih dahulu dan apabila sudah memiliki akun maka prosesnya langsung menuju login saja. Jika berhasil tervalidasi maka anda akan menuju ke halaman utama. Dihalaman utama ada proses pengecekkan akun yang sudah memiliki profile. Jika belum memiliki profile maka diwajibkan untuk melengkapi profile terlebih dahulu dan jika sudah melengkapi profile sebelumnya maka proses ini di lewati. Selanjutnya user akan ditawarkan 2 opsi yaitu pengendara dan penumpang. Jika sebagai pengendara user diharuskan membuat perjalanan terlebih dahulu seperti yang di jelaskan pada gambar di atas. Jika user sebagai penumpang maka user akan mencari tumpangan sesuai tempat awal dan tujuan lalu memesan kursi pada tumpangan tersebut. Jika proses pengecekan tumpangan valid maka penumpang akan mengirimkan notifikasi kepada pengendara yang memiliki tumpangan tersebut. setelah itu proses mengupdate status tumpangan akan dilakukan oleh pengendara dan masing-masing akan mengirim notifikasi kepada penumpang sebagai tanda berangkat dan selesainya tumpangan yang telah dipesan. Namun disini apabila ingin menampilkan rute perjalanan ada proses penerapan algoritma Spatial Map Matching terlebih dahulu untuk mendapatkan posisi tumpangan yang presisi yang akan di tampilkan di maps digital.

Aplikasi yang dikembangkan hanya memiliki satu aktor yaitu Pengguna. 
Volume 10 Number 1. Mei 2020 Page. 45-56

Journal Homepage : http://teknois.stikombinaniaga.ac.id/index.php/JBS

DOI Link : http://doi.org/10.36350/jbs.v10i1

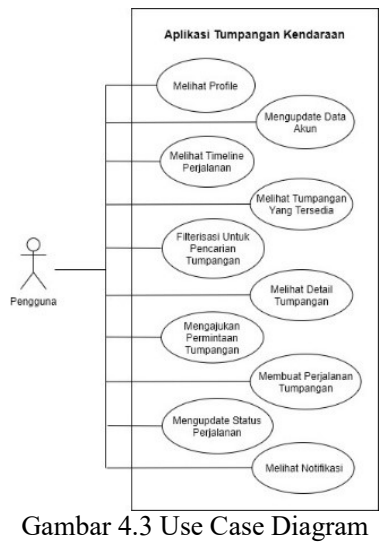

Pada gambar 4.4 dibawah ini merupakan relasi antar tabel yang terdapat pada aplikasi tumpangan kendaraan.

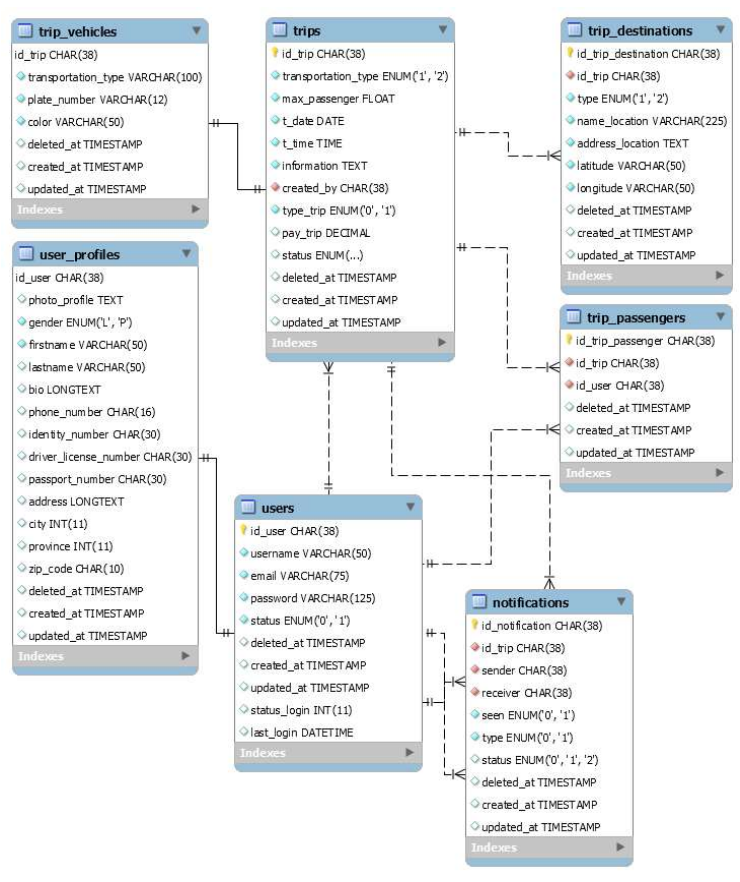

Gambar 4.4 Relasi Antar Tabel

Alur Sistem menggambarkan bagaimana detail dari komponen yang di-terdapat dalam struktur sistem, dimana komponen akan diletakan pada mesin, server atau perangkat keras. Berikut ini adalah gambaran untuk alur sistem pada penerapan Algoritma Spatial Map Matching Dengan API Menggunakan GPS.

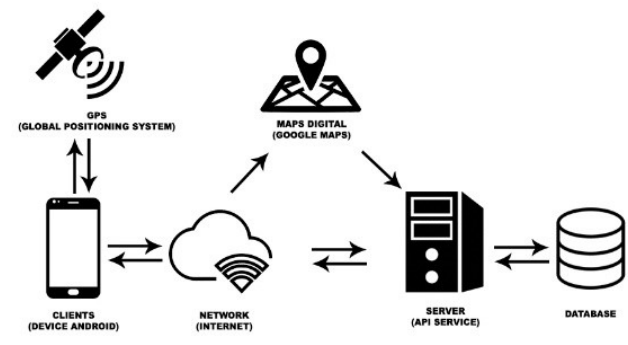

Gambar 4.5 Alur Sistem

Berdasarkan gambar 4.5 dapat kita ketahui sebenarnya proses awal dari aplikasi ini di device android, akan tetapi kita terlebih dahulu harus mengaktifkan fitur GPS (Global Positioning System) agar dapat menerima dan mengirim kan data kedalam maps digital (Google Maps). Setelah itu device android harus terkoneksi dengan internet agar dapat mengakses maps digital yaitu google maps yang terdapat dalam aplikasi. Selain itu juga agar dapat bisa mengakses server API Service untuk memproses semua kegiatan yang ada di aplikasi baik menerima mau pun mengirimkan data semuanya di olah kedalam bentuk JSON. Selanjutnya API Service akan 
mengirim data ke dalam database dan mendapatkan data dari database sesuai apa yang di diproses oleh API Service.

\section{PEMBAHASAN}

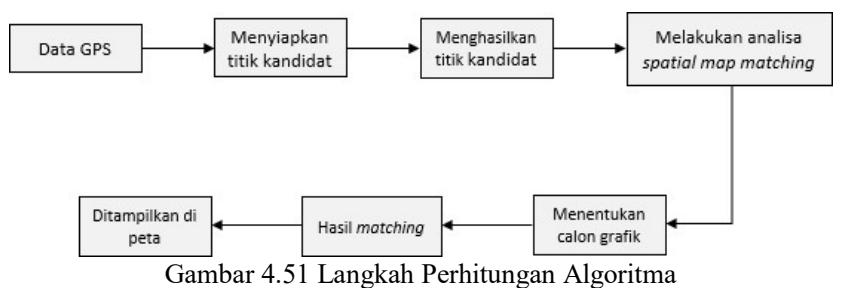

a. Data GPS

Di bawah ini merupakan data dari titik-titik yang ditampilkan kedalam peta :

\begin{tabular}{|c|c|c|}
\hline \multicolumn{3}{|c|}{ Tabel 4.1 Daftar Titik Koordinat } \\
\hline Titik GPS & Latitude & Longitude \\
\hline $\mathrm{P}_{1}$ & -6.5953875 & 106.7592513 \\
\hline $\mathrm{P}_{2}$ & -6.4844686 & 106.8421998 \\
\hline $\mathrm{P}_{3}$ & -6.6046257 & 106.806775 \\
\hline $\mathrm{P}_{4}$ & -6.5686226 & 106.8084463 \\
\hline
\end{tabular}

\begin{tabular}{|c|c|c|c|}
\hline \multicolumn{5}{|c}{ Tabel 4.2 Daftar Titik Kandidat Yang Disiapkan } & Jarak ke P \\
\hline Titik Kandidat & Latitude & Longitude & 0.09 \\
\hline$C_{1}^{1}$ & -6.5954133 & 106.7600393 & 0.22 \\
\hline$C_{1}^{2}$ & -6.5934692 & 106.7598052 & 1.65 \\
\hline$C_{1}^{3}$ & -6.5878869 & 106.7721608 & 0.06 \\
\hline$C_{2}^{1}$ & -6.484881 & 106.842522 & 0.07 \\
\hline$C_{2}^{2}$ & -6.484997 & 106.8424717 & 0.17 \\
\hline$C_{2}^{3}$ & -6.4845879 & 106.8437365 & 0.02 \\
\hline$C_{3}^{1}$ & -6.6045108 & 106.8068764 & 0.02 \\
\hline$C_{3}^{2}$ & -6.6045108 & 106.8068764 & 0.02 \\
\hline$C_{3}^{3}$ & -6.604592 & 106.8069359 & 0.01 \\
\hline$C_{4}^{1}$ & -6.5686938 & 106.8084799 & 0.07 \\
\hline$C_{4}^{3}$ & -6.5688051 & 106.8090462 & 0.07 \\
\hline
\end{tabular}

\section{b. Analisa Spatial Map Matching}

Setelah data-data sebagai inputannya telah didapatkan, maka langkah selanjutnya melakukan analisis spasial. Analisis spasial dilakukan untuk mengolah titik kandidat yang relevan bagi titik GPS dengan mengevaluasi dari segi informasi geometris serta topologi jaringan jalan. Pada analisis spasial terdapat beberapa tahap perhitungan, yaitu probabilitas observasi dan probabilitas transmisi.

Langkah awal dilakukan perhitungan distribusi normal untuk menentukan bobot dari titik kandidat sekaligus sebagai penentuan probabilitas observasi. Probabilitas observasi sendiri akan melakukan sampling titik GPS berdasarkan jarak terdekat dari jalur jalan. Perhitungannya menggunakan persamaan yang akan dijelaskan seperti berikut ini :

$$
N\left(c_{i}^{j}\right)=\frac{1}{\sqrt{7 \pi \sigma}} e^{\frac{-\left(x_{i}^{j}-\mu\right)^{2}}{2 c^{2}}}
$$

Dimana $x_{i}^{j}=\operatorname{dist}\left(\mathcal{L}_{\mathrm{i}}, \mathrm{p}_{i}\right)$ adalah jarak antara $p_{i}$ dan $\epsilon_{i \mathrm{i}}^{j}$ probabilitas observasi tidak memperhitungkan konteks posisi dari titik GPS, sehingga terkadang menyebabkan hasil pencocokan titik yang salah. Maka untuk menghindari hal tersebut digunakan perhitungan probabilitas transmisi agar titik GPS yang melenceng dapat diminimalisir dan dapat dicocokkan ke titik yang seharusnya berada.

Setelah dilakukan perhitungan, maka didapatkan hasil probabilitas observasi seperti dibawah ini.

\begin{tabular}{|l|l|l|l|l|l|l|l|l|l|l|l|}
\hline$c_{1}^{1}$ & $c_{1}^{2}$ & $c_{1}^{3}$ & $c_{2}^{1}$ & $c_{2}^{2}$ & $c_{2}^{3}$ & $c_{3}^{1}$ & $c_{3}^{2}$ & $c_{3}^{3}$ & $c_{4}^{1}$ & $c_{4}^{2}$ & $c_{4}^{3}$ \\
\hline 0,08917 & 0,08918 & 0,08909 & 0,08919 & 0,08919 & 0,08920 & 0,08919 & 0,08919 & 0,08919 & 0,08920 & 0,08920 & 0,08920 \\
11 & 54 & 46 & 46 & 54 & 11 & 96 & 96 & 96 & 16 & 39 & 39 \\
\hline
\end{tabular}

Kemudian tahap selanjutnya melakukan perhitungan dengan menggunakan probabilitas transmisi. Probabilitas transmisi merupakan perhitungan antara jarak titik kandidat terdekat sebelumnya dengan titik kandidat selanjutnya berdasarkan titik poin GPS yang berdekatan. 
Volume 10 Number 1. Mei 2020 Page. 45-56

Journal Homepage : http://teknois.stikombinaniaga.ac.id/index.php/JBS

DOI Link : http://doi.org/10.36350/jbs.v10i1

Perhitungan ini bertujuan untuk mencari titik kandidat yang terbaik. Perhitungannya dilakukan dengan langkah berikut contohnya :

$$
V\left(C_{i-1}^{t} \rightarrow C_{i}^{s}\right)=\frac{d_{i-1 \rightarrow i}}{w_{(i-1, t) \rightarrow(i, s)}}
$$

Dari rumus-rumus yang telah didapat diatas, maka persamaan dari spatial analysis dapat dinyatakan seperti berikut ini sebagai gabungan dari probabilitas observasi dan probabilitas transmisi:

$$
F_{s}\left(C_{i-1}^{\tau} \rightarrow C_{i}^{s}\right)=N\left(C_{i}^{j}\right) \times V\left(C_{i-1}^{\pi} \rightarrow C_{i}^{s}\right), 2 \leq i \leq n
$$

Dimana $C_{i-1}^{t}$ dan $C_{i}^{S}$ adalah dua titik kandidat untuk dua titik GPS bersebelahan $p_{i-1}$ dan $p_{i}$. Setelah melakukan perhitungan, hasil nilainya akan ditampung pada sebuah tabel probabilitas transmisi yang disimbolkan dengan V. Sehingga akan diperoleh hasil bobot hitung seperti pada tabel berikut:

V:

\begin{tabular}{|c|c|c|c|}
\multicolumn{4}{c}{ Tabel 4.4 Data Probabilitas Transmisi } \\
\hline & $\rightarrow C_{2}^{1}$ & $\rightarrow C_{2}^{2}$ & $\rightarrow C_{2}^{3}$ \\
\hline$C_{1}^{1}$ & 1,0042670311366517 & 1,0051638308767878 & 0,997299409935794 \\
\hline$C_{1}^{2}$ & 1,0146507967588039 & 1,0155640581604202 & 1,0074815743605423 \\
\hline$C_{1}^{3}$ & 1,1103141527088636 & 1,1114203343252465 & 1,1020989793380755 \\
\hline & $\rightarrow C_{3}^{1}$ & $\rightarrow C_{3}^{2}$ & $\rightarrow C_{3}^{3}$ \\
\hline$C_{2}^{1}$ & 1,0035474241690272 & 1,0035474241690272 & 1,003058428897417 \\
\hline$C_{2}^{2}$ & 1,0045576563564462 & 1,0045576563564462 & 1,0040675980929388 \\
\hline$C_{2}^{3}$ & 0,9984892250130502 & 0,9984892250130502 & 0,9980106529283669 \\
\hline & $\rightarrow C_{4}^{1}$ & $\rightarrow C_{4}^{2}$ & $\rightarrow C_{4}^{3}$ \\
\hline$C_{3}^{1}$ & 1,0052714059144425 & 1,007556372563224 & 1,0097228872186124 \\
\hline$C_{3}^{2}$ & 1,0052714059144425 & 1,007556372563224 & 1,0097228872186124 \\
\hline$C_{3}^{3}$ & 1,0030748063125046 & 1,0053782212734903 & 1,007535271763117 \\
\hline
\end{tabular}

Setelahnya akan dilakukan perhitungan nilai spasialnya yang nilainya ditentukan dari hasil perkalian titik kandidat $\mathrm{n}$ ke titik kandidat ke-n.

maka hasilnya diisikan ke dalam tabel hasil analisis spasial dengan dinyatakan oleh simbol F seperti di bawah ini.

Fs :

Tabel 4.5 Hasil Analisis Spasial

\begin{tabular}{|c|c|c|c|}
\hline & $\rightarrow C_{2}^{4}$ & $\rightarrow C_{2}^{2}$ & $\rightarrow C_{2}^{3}$ \\
\hline$C_{1}^{1}$ & 0,08955159586018949 & 0,08963156447949713 & 0,08893028541332569 \\
\hline$C_{1}^{2}$ & 0,09049203716925262 & 0,09057348675266033 & 0,08985264720197471 \\
\hline$C_{1}^{3}$ & 0,09892299530993512 & 0,0990215501185741 & 0,0981910677245341 \\
\hline & $\rightarrow C_{3}^{1}$ & $\rightarrow C_{3}^{2}$ & $\rightarrow C_{3}^{3}$ \\
\hline$C_{2}^{1}$ & 0,0895110110797867 & 0,0895110110797867 & 0,08946739534213355 \\
\hline$C_{2}^{2}$ & 0,08960192198177576 & 0,08960192198177576 & 0,0895582110389389 \\
\hline$C_{2}^{3}$ & 0,08906633720931159 & 0,089066333720931159 & 0,08902364805292855 \\
\hline & $\rightarrow C_{4}^{1}$ & $\rightarrow C_{4}^{2}$ & $\rightarrow C_{4}^{3}$ \\
\hline$C_{3}^{1}$ & 0,08966980729900591 & 0,08987362541009056 & 0,090066877765074534 \\
\hline$C_{3}^{2}$ & 0,08966980729900591 & 0,08987362541009056 & 0,09006687765074534 \\
\hline$C_{3}^{3}$ & 0,08947387149315289 & 0,08967933518630683 & 0,08987174322716134 \\
\hline
\end{tabular}

\section{c. Hasil Matching}

Untuk memudahkan proses pencocokan atau matching, dikumpulkan data sebagai berikut ini yang merupakan hasil perhitungan sebelumnya. Data yang digunakan meliputi hasil nilai probabilitas observasi, probabilitas transmisi, dan analisis spasial. 
Volume 10 Number 1. Mei 2020 Page. 45-56

Journal Homepage : http://teknois.stikombinaniaga.ac.id/index.php/JBS

DOI Link : http://doi.org/10.36350/jbs.v10i1

Tabel 4.6 Hasil Nilai Probabilitas Observasi

\begin{tabular}{|l|l|l|l|l|l|}
\hline$c_{1}^{1}$ & $c_{1}^{2}$ & $c_{1}^{3}$ & $c_{2}^{1}$ & $c_{2}^{2}$ & $c_{2}^{3}$ \\
\hline 0,0891711 & 0,0891854 & 0,0890946 & 0,0891946 & 0,0891954 & 0,0892011 \\
\hline$c_{3}^{1}$ & $c_{3}^{2}$ & $c_{3}^{3}$ & $c_{4}^{1}$ & $c_{4}^{2}$ & $c_{4}^{3}$ \\
\hline 0,0891996 & 0,0891996 & 0,0891996 & 0,0892016 & 0,0892039 & 0,0892039 \\
\hline
\end{tabular}

Tabel 4.7 Hasil Nilai Probabilitas Transmisi

\begin{tabular}{|c|c|c|c|}
\hline & $\rightarrow C_{2}^{1}$ & $\rightarrow C_{2}^{2}$ & $\rightarrow C_{2}^{3}$ \\
\hline$C_{1}^{1}$ & 1,0042670311366517 & 1,0051638308767878 & 0,997299409935794 \\
\hline$C_{1}^{2}$ & 1,0146507967588039 & 1,0155640581604202 & 1,0074815743605423 \\
\hline$C_{1}^{3}$ & 1,1103141527088636 & 1,1114203343252465 & 1,1020989793380755 \\
\hline & $\rightarrow C_{3}^{1}$ & $\rightarrow C_{3}^{2}$ & $\rightarrow C_{3}^{3}$ \\
\hline$C_{2}^{1}$ & 1,0035474241690272 & 1,0035474241690272 & 1,003058428897417 \\
\hline$C_{2}^{2}$ & 1,0045576563564462 & 1,0045576563564462 & 1,0040675980929388 \\
\hline$C_{2}^{3}$ & 0,9984892250130502 & 0,9984892250130502 & 0,9980106529283669 \\
\hline & $\rightarrow C_{4}^{1}$ & $\rightarrow C_{4}^{2}$ & $\rightarrow C_{4}^{3}$ \\
\hline$C_{3}^{1}$ & 1.0052714059144425 & 1,007556372563224 & 1,0097228872186124 \\
\hline$C_{3}^{2}$ & 1,0052714059144425 & 1,007556372563224 & 1,0097228872186124 \\
\hline$C_{3}^{3}$ & 1,0030748063125046 & 1,0053782212734903 & 1,007535271763117 \\
\hline
\end{tabular}

\begin{tabular}{|c|c|c|c|}
\hline \multicolumn{4}{|c}{ Tabel 4.8 Hasil Nilai Analisis Spasial } \\
\hline$C_{1}^{1}$ & 0,08955159586018949 & $\rightarrow C_{2}^{2}$ & $\rightarrow C_{2}^{3}$ \\
\hline$C_{1}^{2}$ & 0,09049203716925262 & 0,08963156447949713 & 0,08893028541332569 \\
\hline$C_{1}^{3}$ & 0,09892299530993512 & 0,09057348675266033 & 0,08985264720197471 \\
\hline & $\rightarrow C_{3}^{1}$ & 0,0990215501185741 & 0,0981910677245341 \\
\hline$C_{2}^{1}$ & 0,0895110110797867 & $\rightarrow C_{3}^{2}$ & $\rightarrow C_{3}^{3}$ \\
\hline$C_{2}^{2}$ & 0,08960192198177576 & 0,08960192198177576 & 0,0895582110389389 \\
\hline$C_{2}^{3}$ & 0,08906633720931159 & 0,08906633720931159 & 0,08902364805292855 \\
\hline & $\rightarrow C_{4}^{1}$ & $\rightarrow C_{4}^{2}$ & $\rightarrow C_{4}^{3}$ \\
\hline$C_{3}^{1}$ & 0,08966980729900591 & 0,08987362541009056 & 0,09006687765074534 \\
\hline$C_{3}^{2}$ & 0,08966980729900591 & 0,08987362541009056 & 0,09006687765074534 \\
\hline$C_{3}^{3}$ & 0,08947387149315289 & 0,08967933518630683 & 0,08987174322716134 \\
\hline
\end{tabular}

Berikut merupakan tabel kosong sebagai contoh pencarian kandidat yang relevan selanjutnya.

\begin{tabular}{|l|l|l|l|l|l|}
\multicolumn{7}{|c|}{ Tabel 4.9 Tabel Kosong Pencarian Kandidat Yang Relevan } \\
\hline$c_{1}^{1}$ & $c_{1}^{2}$ & $c_{1}^{3}$ & $c_{2}^{1}$ & $c_{2}^{2}$ & $c_{2}^{3}$ \\
\hline 0,0891711 & 0,0891854 & 0,0890946 & & & \\
\hline$c_{3}^{1}$ & $c_{3}^{2}$ & $c_{3}^{3}$ & $c_{4}^{1}$ & $c_{4}^{2}$ & $c_{4}^{3}$ \\
\hline & & & & & \\
\hline
\end{tabular}

Setelah melakukan perhitungan dan mencari nilai max dari masing- masing kandidat, maka hasil dari perhintaungan dimasukkan ke dalam tabel hasil akhir proses matching dan sekaligus langkah terakhir dari metode Spatial Map Matching, hasilnya menjadi seperti berikut ini:

\begin{tabular}{|l|l|l|l|l|l|}
\multicolumn{7}{|c|}{ Tabel 4.10 Hasil Akhir Proses Matching } \\
\hline$e_{1}^{1}$ & $e_{1}^{2}$ & $e_{1}^{3}$ & $e_{2}^{1}$ & $e_{2}^{z}$ & $e_{2}^{3}$ \\
\hline 0,0891711 & 0,0891854 & 0,0890946 & 0,0988913 & 0,098911 & 0,0987476 \\
\hline$e_{5}^{\frac{1}{1}}$ & $e_{5}^{2}$ & $e_{8}^{3}$ & $e_{4}^{1}$ & $e_{4}^{2}$ & $e_{4}^{3}$ \\
\hline 0,1069399 & 0,1069399 & 0,1069321 & 0,1149808 & 0,1150176 & 0,1150523 \\
\hline
\end{tabular}

Berdasarkan tabel tersebut dapat diketahui jika masing-masing kandidat untuk pencocokan titik GPS untuk pencarian jalur terbaik dengan melihat nilai bobot terbesar. Maka jalur yang ditentukan sebagai yang terbaik adalah:

(C2020 Teknois : Jurnal Ilmiah Teknologi Informasi dan Sains. Copyrights All rights reserved 
Volume 10 Number 1. Mei 2020 Page. 45-56

Journal Homepage : http://teknois.stikombinaniaga.ac.id/index.php/JBS

DOI Link : http://doi.org/10.36350/jbs.v10i1

$$
c_{1}^{2} \rightarrow c_{2}^{2} \rightarrow c_{3}^{1} \rightarrow c_{4}^{3}
$$

Tabel 4.11 Perbandingan Data Koordinat Sebelum Dan Setelah Diproses

\begin{tabular}{|c|l|l|l|c|}
\hline No & \multicolumn{1}{|c|}{ Latitude Awal } & \multicolumn{1}{|c|}{ Latitude Akhir } & \multicolumn{1}{|c|}{ Longitude Awal } & Longitude Akhir \\
\hline 1 & -6.5953875 & -6.5934692 & 106.7592513 & 106.7598052 \\
\hline 2 & -6.4844686 & -6.484997 & 106.8421998 & 106.8424717 \\
\hline 3 & -6.6046257 & -6.6045108 & 106.806775 & 106.8068764 \\
\hline 4 & -6.5686226 & -6.5688816 & 106.8084463 & 106.8090397 \\
\hline
\end{tabular}

Berdasarkan tabel tersebut dapat kita lihat titik-titik koordinat sebelum dan sesudah melakukan penerapan Algoritma Spatial Map Matching. Dari tabel tersebut kita dapat lihat perbedaannya.

\section{KESIMPULAN}

Berdasarkan hasil penelitian yang dilakukan, kesimpulan yang bisa diuraikan antara lain :

1. Pada penelitian yang telah dilakukan, hasilnya menunjukkan bahwa metode Spatial Map Matching berhasil memperbaiki posisi kendaraan yang tidak tepat menjadi lebih presisi pada jalan yang semestinya.

2. Dapat mempermudah mendapatkan posisi tumpangan kendaraan pada Maps Digital (Google Maps) dengan penerapan Algoritma Spatial Map Matching.

3. Setelah melakukan perhitungan jarak untuk mengetahui seberapa presisi titik koordinat yaitu dengan menyiapkan sampel sebanyak 15 data dan kondisi perhitungan yang sama. bahwa dari 15 data titik yang ditentukan, data jarak dari penerapan Algoritma Spatial Map Matching lebih dekat dibandingkan dengan data jarak aplikasi sebelumnya (nebengers) terhadap posisi tempat/jalan terdekat yang sudah ditentukan yaitu dengan rata-rata jaraknya 1.71 Meter. Sedangkan hasil selisih jarak yang dihasilkan memiliki jarak yang cukup jauh antara jarak data dari posisi titik pada aplikasi sebelumnya (nebengers) dengan posisi titik yang sudah diterapkan Algoritma Spatial Map Matching. Dapat disimpulkan bahwa Algoritma Spatial Map Matching dapat menentukan titik posisi yang lebih Presisi.

Berdasarkan hasil analisis data kuesioner penerapan Algoritma Spatial Map Matching dapat berfungsi dengan baik dan dinyatakan layak dengan nilai persentase kelayakan sebesar $82,85 \%$.

\section{E. DAFTAR RUJUKAN}

[1] Andi. 2009. Global Positioning System, Penerbit Andi, Yogyakarta.

[2] Anwar, B. Jaya, H. dan Kusuma, P.I. (2014). Implementasi Location Based Service Berbasis Android Untuk Mengetahuiposisi User. STMIK Triguna Dharma.

Badan Pusat Statistik. 2018. Perkembangan Jumlah Kendaraan Bermotor Menurut Jenis, 1949-2018

[3] [online]. Ada di: https://www.bps.go.id/linkTableDinamis/view/id/1133 [Diakses tanggal 27 Agustus 2019]

Ghaniy, Rajib, and Rizki Darmawan. "Analisa dan Penerapan Algoritma Floyd Warshal untuk

[4] Optimalisasi Jalur Berbasis GPS." Teknois, vol. 8, no. 2, Nov. 2018, pp. 67-78, doi: $10.36350 /$ jbs.v8i2.16.

[5] G. R. Jagadeesh, T. Srikanthan, X. D. dan Zhang. (2004). A Map Matching Method for GPS Based Real-Time Vehicle Location. Nanyang Technological University.

[6] Harijanto, F. dan Widyantara, H. (2008). Sistem Pemantauan Posisi Mobil Menggunakan Global Positioning System (GPS) Berbasiskan Radio Frekuensi. STIKOM Surabaya.

[7] Huang, Z. Huang, D. Xu, Zhu. dan Xu, Zhigen. (2011). GPS Vehicle Positioning Monitoring System Integrated with CORS and Mobile GIS. Southwest Jiaotong University.

[8] Ihsanto, E. Eng, M. dan Riyanto, T.W. (2013). Disain Dan Implementasi Sistem Penjejak Posisi Kendaraan Dengan GPS Via SMS. Universitas Mercu Buana Jakarta.

[9] Junus, M. (2012). Sistem Pelacakan Posisi Kendaraan Dengan Teknologi GPS \& GPRS Berbasis Web, hal. 58-67.

[10] Maftukhin, M.R. (2018). Implemetasi Algoritma Spatial Map Matching Untuk Mengetahui Lokasi Kendaraan Melalui Aplikasi GPS.

[11] Maskeri, G. Rama. dan Avinash, K. 2015. Software - Practice and Experience. New Jersey: Wiley Online Library.

[12] Rahman, A.L. Ahmad, T. dan Studiawan, H. (2013). Aplikasi Tumpangan Kendaraan Berbasis Android Dengan Google Maps dan GPS. Institut Teknologi Sepuluh Nopember.

[13] Winardi. 2006. Penentuan Posisi Dengan GPS Untuk Survei Terumbu Karang, Puslit Oseanografi Lipi, Jakarta.

[14] Yuan, J. Zheng, Y. Zhang. C. Xie, X. dan Sun, Guang-Zhong. (2010). An Interactive-Voting Based Map Matching Algorithm. Eleventh International Conference on Mobile Data Management. 